\title{
Tumor Necrosis Factor Receptor-Associated Factor 6 (TRAF6) Deficiency Results in Exencephaly and Is Required for Apoptosis within the Developing CNS
}

\author{
Mark A. Lomaga, ${ }^{1,3}$ Jeffrey T. Henderson, ${ }^{2}$ Andrew J. Elia, ${ }^{3}$ Jennifer Robertson, ${ }^{2}$ Ryan S. Noyce, ${ }^{3}$ \\ Wen-Chen Yeh, ${ }^{3,4}$ and Tak W. Mak ${ }^{1,3,4}$ \\ 1 Department of Pharmaceutical Sciences, Faculty of Pharmacy, University of Toronto, Toronto, Ontario, Canada M5S 2S2, \\ 2Samuel Lunenfeld Research Institute, Program in Molecular Biology and Cancer, Mount Sinai Hospital, Toronto, Ontario, \\ Canada M5G 1X5, 3Amgen Institute, Toronto, Ontario, Canada M5G 2C1, and ${ }^{4}$ Ontario Cancer Institute and Departments \\ of Medical Biophysics and Immunology, University of Toronto, Ontario, Canada M5G 2 M9
}

\begin{abstract}
Tumor necrosis factor receptor-associated factors (TRAFs) are adaptor proteins important in mediating intracellular signaling. We report here that targeted deletion of traf6 greatly increases the frequency of failure of neural tube closure and exencephaly in traf6 (-/-) mice. The penetrance of this defect is influenced by genetic background. Neural tube fusion requires the coordination of several biological processes, including cell migration invoked by contact-dependent signaling, cell proliferation, and programmed cell death (PCD). To gain greater insight into the role of TRAF6 in these processes, neural development and migration within the CNS of traf6 (-/-) mice and controls were assessed through temporal examination of a number of immunohistochemical markers. In addition, relative levels of cellular proliferation and PCD were examined throughout embryonic develop-
\end{abstract}

ment using bromodeoxyuridine (BrdU) and in situ terminal deoxynucleotidyl transferase-mediated dUTP biotinylated nick end labeling (TUNEL), respectively. The data suggest that loss of TRAF6 does not significantly alter the level of cellular proliferation or the pattern of neural differentiation per se, but rather regulates the level of PCD within specific regions of the developing CNS. Substantial reductions in TUNEL were observed within the ventral diencephalon and mesencephalon in exencephalic traf6 $(-/-)$ embryos. Our results demonstrate a novel and prominent role for TRAF6 in the regional control of PCD within the developing CNS.

Key words: programmed cell death; TUNEL; CNS; thalamus; diencephalon; neural tube closure; gene targeting
Tumor necrosis factor receptor (TNFR)-associated factors (TRAFs) belong to a family of intracellular adaptor proteins that mediate signaling downstream of various cell surface receptors, including members of the TNFR superfamily (Arch et al., 1998). TR AF family members have been described in mammals, Drosophila, and Caenorhabditis elegans and are characterized by conserved structural motifs (Rothe et al., 1994; Cao et al., 1996; Muhlenbeck and Scheurich, 1998; Liu et al., 1999). The TRAF C-terminal domain is thought to mediate TRAF-TRAF and TRAF-receptor interactions, whereas the N-terminal RING finger and zinc finger consensus sequences appear to be essential for downstream signal transduction (Rothe et al., 1995; Cao et al., 1996; Takeuchi et al., 1996).

The physiological roles of TRAF2, $-3,-5$, and -6 have been defined using gene-targeted mice (Xu et al., 1996; Yeh et al., 1997; Lomaga et al., 1999; Naito et al., 1999; Nakano et al., 1999). A characteristic phenotype of TRAF-deficient mice is immune system dysfunction that appears to be related to defective activation of kinases such as the c-Jun N-terminal kinases (JNKs) and/or of transcription factors such as nuclear factor kappa B $(\mathrm{NF}-\kappa \mathrm{B})$. TRAF6 is structurally the most divergent member of the TRAF family (Cao et al., 1996), and the phenotypes exhibited by TRAF6deficient mice are more varied than those of other TRAF knockout mice. We previously reported that traf6 $(-/-)$ mice are osteopetrotic, with defects in bone remodeling and tooth eruption because

\footnotetext{
Received May 10, 2000; revised July 6, 2000; accepted July 19, 2000.

We are grateful to the members of the Henderson and Mak labs for helpful discussions and advice. We also thank Douglas Holmyard for electron microscopy assistance and support, Irene $\mathrm{Ng}$ for excellent administrative support, and Mary Saunders for scientific editing of this manuscript.

M.A.L. and J.T.H. contributed equally to this work.

Correspondence should be addressed to Tak W. Mak, Amgen Institute, 620 University Avenue, Toronto, Ontario, Canada M5G 2C1. E-mail: tmak@oci.utoronto.ca. Copyright (C) 2000 Society for Neuroscience $0270-6474 / 00 / 207384-10 \$ 15.00 / 0$
}

of impaired osteoclast function (Lomaga et al., 1999). TRAF6 has also been shown to play crucial roles in lymph node organogenesis and interleukin-1 (IL-1), CD40, and LPS signaling (Lomaga et al., 1999; Naito et al., 1999). In addition, TRAF6 appears to be essential for perinatal survival and possibly embryogenesis (Lomaga et al., 1999; Naito et al., 1999).

Exencephaly is an embryonic-lethal condition defined by protrusion of the brain from the skull. In humans, neural tube defects (NTDs) occur at a worldwide frequency of $0.1-0.9 \%$ of total births (Neumann et al., 1994). In mice, at least 50 single-gene mutations have been reported to cause NTDs (Harris and Juriloff, 1999). Although the etiologies of these defects are not fully understood, both genetic and environmental factors are believed to be involved (Copp et al., 1990; Smith and Schoenwolf, 1997).

The process of neural tube (NT) closure involves the proper orchestration of several biological processes, including cellular migration and differentiation, proliferation, and apoptosis (Harris and Juriloff, 1999). We set out to determine the role of TRAF6 in governing NT closure by systematically examining CNS development in traf6 $(-/-)$ embryos and control littermates at various stages of gestation using several well characterized immunohistochemical markers. Cellular proliferation and levels of apoptosis within the developing CNS were examined using BrdU and TUNEL incorporation assays, respectively. The data presented in this report indicate that TRAF6 does not play a prominent role in mediating cellular differentiation, migration, or proliferation during CNS development. Surprisingly, however, traf6 (-/-) embryos exhibit significant reductions in PCD within the developing ventral diencephalon and mesencephalon. As a result, a significant expansion of these regions ensues. Thus, TRAF6 appears to regulate neural development by controlling the level of PCD in a regionspecific manner within the CNS. These in vivo results therefore demonstrate a novel role for TRAF6 in mediating NT closure and site-specific PCD within the developing CNS. 


\section{MATERIALS AND METHODS}

Generation of traf6 (-/-) embryos. Embryos at various stages of gestation were obtained by establishing timed intercrosses of traf6 $(+/-)$ mice $(129 \mathrm{~J} \times \mathrm{C} 57 / \mathrm{BL} 6$ background) as described previously (Lomaga et al. 1999). To assess the effect of genetic background on the incidence of exencephaly, traf6 $(+/-)$ mice were backcrossed to either inbred (C57) BL6) (Taconic, Germantown, NY) or outbred (ICR/CD1) (Harlan Sprague Dawley) mice. For timed breedings, the morning of the vaginal plug was designated as embryonic day (E) 0.5. Mice were maintained in accordance with the ethical guidelines of the Ontario Cancer Institute animal facility.

Northern blot analysis. A 398 bp murine traf6 cDNA probe (encoding approximately the first 130 amino acids of TR AF6) was radiolabeled and hybridized to a commercially available mouse RNA master blot (Clontech, Palo Alto, CA) per the manufacturer's instructions. The master blot was composed of RNA dot blots containing normalized amounts of poly $\left(\mathrm{A}^{+}\right)$ RNA from 22 different adult mouse tissues and whole embryos at various stages of gestation.

Histology and immunohistochemistry. Mice were deeply anesthetized with sodium pentobarbital (Somnitol $80 \mathrm{mg} / \mathrm{kg}$ ) before they were killed, and embryos from E10.5 to E18.5 were isolated in ice-cold PBS. Samples were fixed overnight in fresh $4 \%$ paraformaldehyde in $0.1 \mathrm{M} \mathrm{PBS}$ at $4{ }^{\circ} \mathrm{C}$, dehydrated, and embedded in paraffin. Serial sets of $7 \mu \mathrm{m}$ sagittal sections were prepared through the central two-thirds of each embryo. The interval between successive slides in a given set was typically $35 \mu \mathrm{m}$. Individual sets were processed and subjected to either (1) TUNEL assay to determine apoptosis, (2) BrdU labeling to assess proliferation, (3) traf6 in situ hybridization to examine gene expression, (4) $0.1 \%$ thionin staining to examine cellularity, or (5) immunohistochemical analysis to determine protein expression, as described below. With the exception of samples used for in situ hybridization, the number of exencephalic traf6 $(-/-)$ and control embryos examined at each age for the described assays was as follows: $\mathrm{E} 10.5, n=2$ traf6 $(-/-), 2$ control; E13.5, $n=3,4 ; \mathrm{E} 14.5, n=6,5 ; \mathrm{E} 15.5$, $n=5,5 ; \mathrm{E} 16.5, n=2,2$; and E18.5, $n=2,2$. For TUNEL, BrdU, and immunohistochemical analyses at E14.5 and E15.5, several sets of sections (data not shown) were also derived in the horizontal plane.

For immunohistochemistry, peroxidase activity was first quenched using $3 \% \mathrm{H}_{2} \mathrm{O}_{2}$ in $100 \%$ methanol for $30 \mathrm{~min}$. Samples were then blocked in $5 \%$

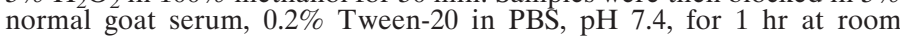
temperature. Primary antibody was added to sections in blocking buffer, and samples were incubated overnight at $4^{\circ} \mathrm{C}$. Sections were incubated with biotinylated secondary antibody at a dilution of 1:200 for $2 \mathrm{hr}$ at room temperature, followed by incubation with streptavidin-HRP (BA-1000; Vector Laboratories, Burlingame, CA) at 1:100 for $1 \mathrm{hr}$ at room temperature and visualization with 3,3 diaminobenzidine (SK-4100; Vector Laboratories). Both anti-calbindin antibody (C-8666; Sigma, St. Louis, MO) and anti-calretinin antibody (AB-149; Chemicon, Temecula, CA) were used at a dilution of 1:400. Anti-GFAP hydroxylase antibody (MAB 360; Chemicon) was used at 1:300, anti-neurofilament light chain antibody (AB-1983; Chemicon) at 1:100, and anti-tyrosine hydroxylase antibody (AB-152; Chemicon) at 1:600. Anti-p75 (Rex) antibody, the kind gift of Dr. L. Riechardt (University of California, San Francisco) was used at 1:2500.
After antibody staining, sections were dehydrated and mounted according to standard procedures.

Scanning electron microscopy. Specimens were fixed in $2 \%$ glutaraldehyde in $0.1 \mathrm{M}$ sodium cacodylate buffer, post-fixed in $1 \%$ osmium tetroxide in $0.1 \mathrm{M}$ sodium cacodylate buffer, and dehydrated in $100 \%$ alcohol. Embryos were then dried in a critical point dryer, mounted on aluminum stubs with carbon paste, and gold sputter-coated. Samples were viewed using a Hitachi S-2500 scanning electron microscope.

BrdU labeling. Cell division (passage through S-phase) was examined by incorporation of the thymidine analog bromodeoxyuridine (B-5002; Sigma) as described previously (Hakem et al., 1998). Briefly, pregnant females were injected intraperitoneally with BrdU (100 $\mu \mathrm{g} / \mathrm{g}$ body weight) and killed 45 min later. Embryos were removed and fixed in $4 \%$ paraformaldehyde overnight at $4^{\circ} \mathrm{C}$. The desired tissues were excised, and samples were prepared as wax specimens. Serial sections of $7 \mu \mathrm{m}$ were prepared through the regions of interest. After dewaxing, sections were incubated for $30 \mathrm{~min}$ in a solution of $0.01 \%$ pepsin, $10 \mathrm{mM} \mathrm{HCl}$ in PBS at $37^{\circ} \mathrm{C}$. After a wash, sections were placed in a solution of $2 \mathrm{~N} \mathrm{HCl}$ for $30 \mathrm{~min}$ at room temperature and neutralized in a solution of $0.1 \mathrm{M}$ sodium borate, $\mathrm{pH} 8.5$, for $10 \mathrm{~min}$. Samples were blocked in a solution consisting of $5 \%$ horse serum, 3\% BSA, and $0.3 \%$ Tween-20 in PBS. Slides were incubated in primary anti-BrdU antibody (Becton Dickenson; cat: 347580 , diluted 1:25 in blocking solution) for 2-3 hr at room temperature. Specimens were washed three times for 5 min each in PBST (PBS plus $0.3 \%$ Triton X-100), followed by several washes in PBS to remove detergent, then incubated for $1 \mathrm{hr}$ in secondary antibody (1:100 dilution of biotinylated anti-mouse antibody in PBS) (Vectastain mouse IgG ABC kit; Vector Laboratories; cat: SK-4100). After washing, specimens were incubated in avidin-HRP (Vectastain ABC kit, as above) at a dilution of 1:100 in PBS for 45-60 min at room temperature. After washing, sections were equilibrated in $100 \mathrm{~mm}$ Tris, $\mathrm{pH} 7.5$, and stained using a Vectastain DAB substrate kit according to the manufacturer's instructions.

TUNEL assay. In situ detection of PCD was determined by TUNEL assay (Boehringer Mannheim, Indianapolis, IN; cat: 1684817) according to the manufacturer's instructions. Briefly, this assay monitors the number of free $3^{\prime} \mathrm{OH}$ termini through terminal deoxynucleotidyl transferase (TdT)dependent incorporation of fluorescein-labeled dUTP. Paraffin sections for TUNEL analysis were dewaxed and equilibrated in PBS, $\mathrm{pH} 7.4$, followed by incubation in proteinase $\mathrm{K}(20 \mu \mathrm{g} / \mu \mathrm{l}$ in $10 \mathrm{~mm}$ Tris-HCl, pH 7.5 ) for $15 \mathrm{~min}$ at $37^{\circ} \mathrm{C}$. The TUNEL reaction mixture containing TdT, labeled nucleotides, and DNA polymerase was applied to sections in a humidified chamber and incubated for $1 \mathrm{hr}$ at $37^{\circ} \mathrm{C}$. Sections were subsequently mounted in antifade medium and photographed using fluorescent optics.

Whole-mount in situ hybridization. Antisense and sense (control) probes for traf6 were derived from an $\sim 200$ bp murine cDNA encoding amino acids 400-467. Briefly, E9.5 wild-type embryos ( $n=7$, ICR/CD1 background) were isolated in ice-cold diethyl pyrocarbonate (Sigma)-treated PBS and fixed overnight in $4 \%$ paraformaldehyde (Sigma) at $4^{\circ} \mathrm{C}$ with agitation. Samples were then hybridized with digoxigenin-UTP-labeled traf6 antisense or sense riboprobes at $65^{\circ} \mathrm{C}$, washed, and developed using nitro-blue tetrazolium salt and 5-bromo-4-chloro-3-indolyl-phosphate

\begin{tabular}{|c|c|c|c|c|c|}
\hline \multirow[b]{2}{*}{ Stage } & \multicolumn{3}{|c|}{ Number genotyped (percentage) } & \multirow{2}{*}{$\begin{array}{l}\% \text { TRAF6 }(-/-) \\
\text { embryos exhibiting } \\
\text { exencephaly }\end{array}$} & \multirow{2}{*}{$\begin{array}{l}\text { Total number of } \\
\text { animals examined } \\
\text { at this stage }\end{array}$} \\
\hline & $+/+$ & $+/-$ & $-1-$ & & \\
\hline \multicolumn{6}{|c|}{ 129J $\times$ C57BL6 } \\
\hline E12.5 & $4(18)$ & $12(55)$ & $6(27)$ & 17 & 22 \\
\hline E13.5 & $6(15)$ & $19(48)$ & $15(37)$ & 33 & 40 \\
\hline E14.5 & $10(19)$ & $27(50)$ & $17(31)$ & 23 & 54 \\
\hline E15.5 & $15(27)$ & $27(48)$ & $14(25)$ & 29 & 56 \\
\hline E16.5 & $3(18)$ & $7(41)$ & $7(41)$ & 71 & 17 \\
\hline E17.5 & $8(27)$ & $15(50)$ & $7(23)$ & 57 & 30 \\
\hline P14 & $104(32)$ & 187 (57) & $36(11)$ & 0 & 327 \\
\hline \multicolumn{6}{|c|}{ ICR/CD1 } \\
\hline P14 & $21(25)$ & $46(55)$ & $17(20)$ & 0 & 84 \\
\hline \multicolumn{6}{|l|}{ C57BL6 } \\
\hline E18.5 & $\begin{array}{r}2(20) \\
{ }^{a} \text { Wild-ty }\end{array}$ & $6(60)$ & $2(20)$ & 100 & 10 \\
\hline $\mathrm{P} 14$ & allele $=$ & & $8(5)$ & 0 & 158 \\
\hline
\end{tabular}

TRAF6 (-/-) animals were derived from timed matings of TRAF6 (+/-) mice, with the morning of the plug designated as E0.5. No exencephaly was observed in TRAF6 $(+/-)$ or $(+/+)$ littermates. P14 represents the number of viable progeny observed at P14 derived from TRAF6 $(+/-)$ mice in the mixed C57BL6 $\times 129 \mathrm{~J}$ background or backcrossed more than two times onto either C57BL6 or outbred ICR/CD1 genetic backgrounds.

${ }^{a}$ Indicates the number of animals exhibiting one or more wild-type allele(s) from intercrosses of C57BL6 TRAF6 (+/-) mice. 

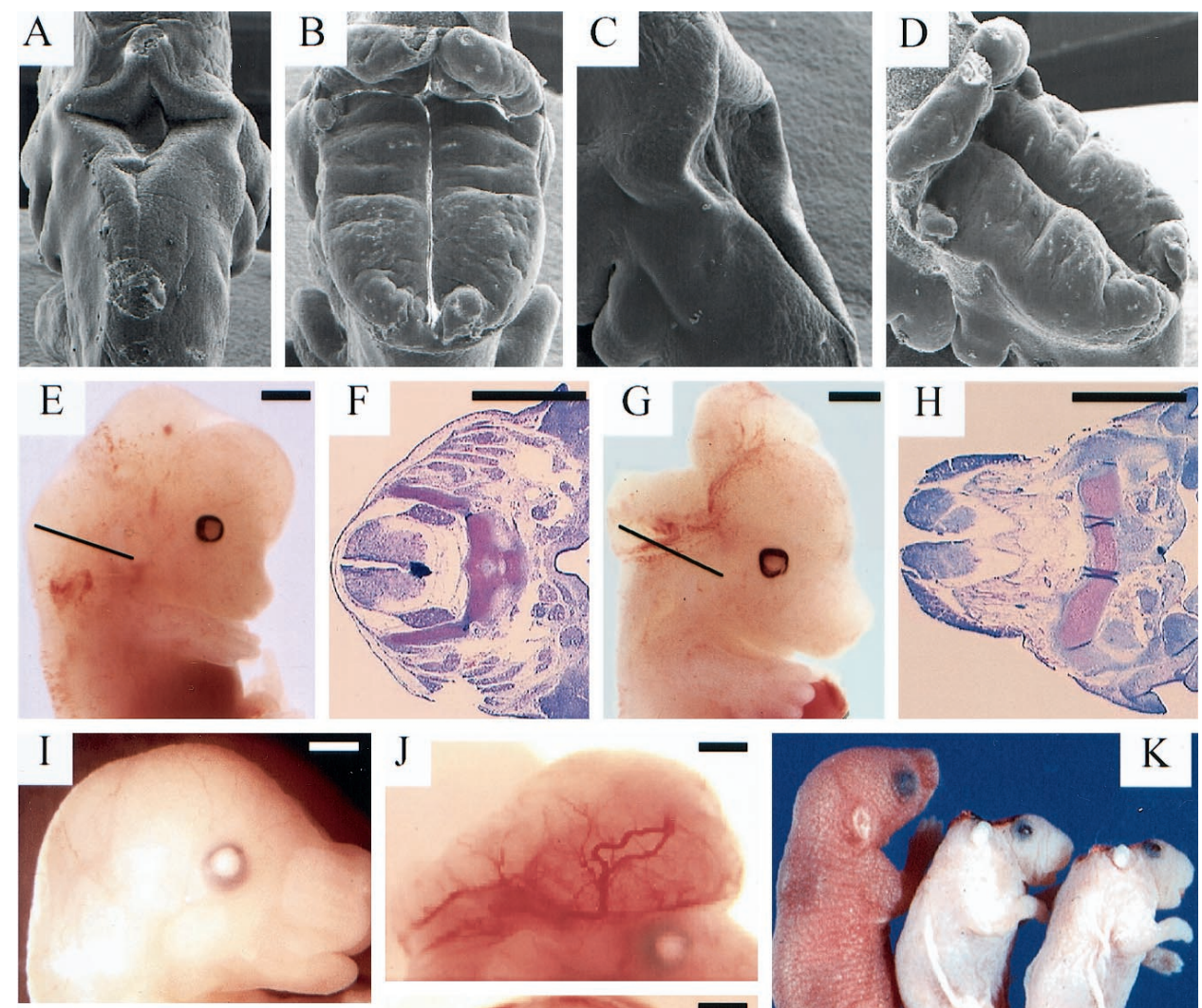

Figure 1. Exencephaly in TRAF6-deficient embryos. $A-D$, Comparison of representative traf6 $(-/-)$ and $(+/-)$ embryos at E10.5 by scanning electron microscopy. $A$, On-axis caudal view of the roof of the hindbrain (fourth ventricle) of a traf6 (+/-) embryo at E10.5 showing NT fusion in progress. $B$, Comparative view of a trafb (- - ) littermate showing failure of NT fusion. $C$, Off-axis caudal view of the roof of the hindbrain of an E10.5 traf6 $(+/-)$ embryo. $D$, Comparative off-axis caudal view of an E10.5 traf6 (-/ ) embryo. $E-H$, Overview and corresponding cross sections of representative trafb $(+/-)$ and exencephalic $(-/-)$ embryos at E13.5. E, Anterior overview and $(F)$ cross section of a representative traf6 (+/-) embryo. $G$, Anterior overview and $(H)$ cross section of a representative traf6 (-/-) embryo. Lines in overviews indicate the relative level of the corresponding thionin-stained cross section. $I$, Overview of an E14.5 traf6 $(+/-)$ embryo. $J$, Overview of two E14.5 exencephalic traf6 $(-/-)$ embryos. $K$, Overviews of a viable traf6 $(+/-)$ and two deceased exencephalic $(-/-)$ littermates at P1. Note the lack of cephalic tissue in traf6 $(-/-)$ as a result of injury during birth. Scale bars $(E-J): 1 \mathrm{~mm}$.
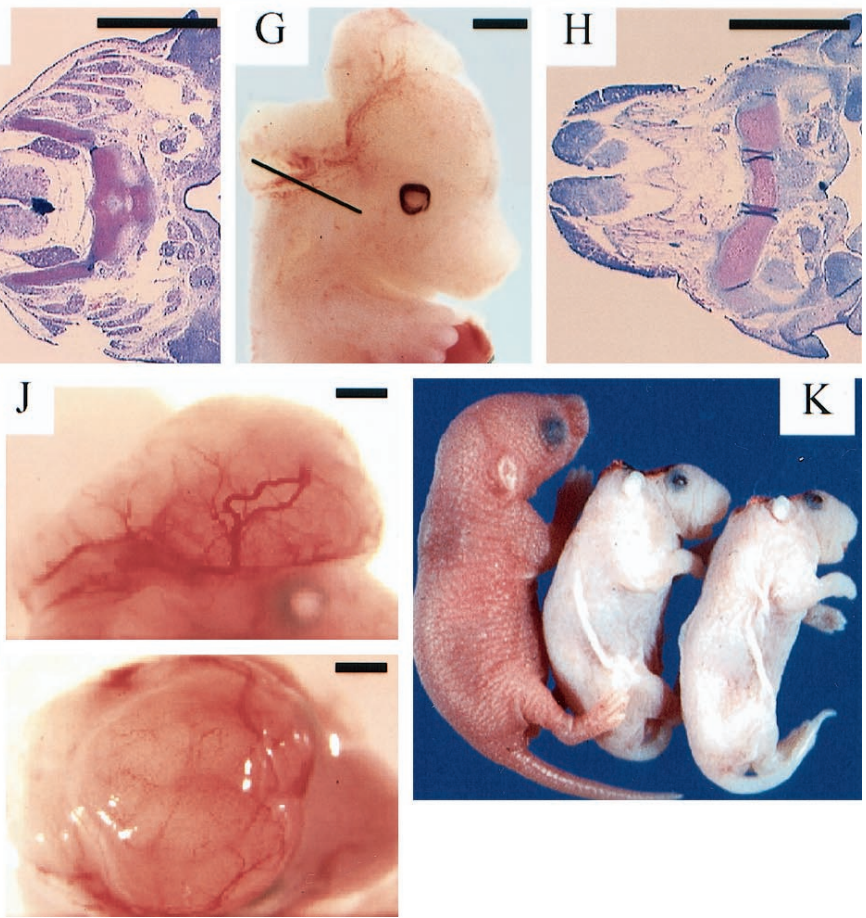

(Boehringer Mannheim) as described previously (de la Pompa et al., 1997; del Barco Barrantes et al., 1999). After development, sections were counterstained with toluidine blue.

\section{RESULTS}

\section{TRAF6 deficiency results in exencephaly}

Heterozygous intercrosses of TRAF6 (+/-) mice yielded lower than expected ratios of traf6 $(-/-)$ progeny on several different genetic backgrounds. As shown in Table 1, postnatal day 14 (P14) traf6 (-/ ) mice represented $11 \%$ of the total population in the mixed 129J/C57BL6 background, 20\% in the outbred ICR/CD1 background, and 5\% in the inbred C57BL6 background. No significant reductions in the numbers of viable traf6 $(-/-)$ animals occurred between P1 and P14 (data not shown). These results indicate that traf6 $(-/-)$ mice died immediately before or after (likely as a process of) birth as a result of trauma to the CNS (Fig. $1 K$ ) and that the extent of perinatal death was influenced by genetic background. Thus the degree of exencephaly/postembryonic lethality is subject to the influence of additional (as yet unidentified) genetic modifiers.

To determine the nature of the perinatal lethality, E10.5-18.5 embryos from traf6 $(+/-)$ matings were isolated. Surprisingly, an overall average of $\sim 35 \%$ of traf6 $(-/-)$ embryos of the mixed 129J/C57BL6 background exhibited failure of NT closure resulting in exencephaly (Table 1). Although scanning EM analysis of the hindbrain regions of traf6 $(+/-)$ embryos showed normal NT closure at E10.5 (Fig. $1 A, C$ ), the lateral ridges failed to elevate in the region of the fourth ventricle in traf6 $(-/-)$ embryos (Fig. $1 B, D)$. Continued cell proliferation along the rostral and lateral margins of the open NT resulted in an accumulation of neuroec- toderm and eversion of the NT. Defects in other regions of the NT were not observed. At E13.5, exencephaly was even more pronounced in affected traf6 $(-/-)$ mutants (Fig. 1, compare $G$ with the traf6 $(+/-)$ embryo in $E)$. Thionin staining of cross sections of these embryos confirmed the failure of NT fusion in the traf6 $(-/-)$ exencephalic embryos (Fig. 1, compare $H$ with the control in $F$ ), and exencephaly continued to be a prominent feature at E14.5 in affected traf6 $(-/-)$ mutants (Fig. 1, compare $J$ with the control in $I)$. The majority of exencephalic traf6 $(-/-)$ mice died shortly before or during parturition as a result of traumatic CNS injury suffered during birth, because this process frequently removed most or all of the exencephalic tissue (Fig. $1 K$ ). Traf6 $(-/-)$ mice also exhibited an overall reduction in body size compared with wild-type littermates.

\section{TRAF6 gene expression in the embryo}

To determine whether traf6 mRNA is expressed during embryonic development, Northern blot analysis was performed on tissues of wild-type mice. In contrast to the low levels of traf6 expressed in various adult organs, high levels of traf6 mRNA were detected at all stages of embryonic development examined (E7-E17) (Fig. 2A). To determine the spatial distribution of traf6 gene expression, wild-type embryos at E9.5 were analyzed by in situ hybridization using an antisense traf6 probe (Fig. $2 B, C$ ). At this developmental stage, traf6 mRNA was strongly expressed in the neuroepithelium of the telencephalic (arrowhead) and mesencephalic vesicles, in the optic stalk, and in the otic vesicles. A traf6 sense probe failed to generate a visible signal (data not shown). 


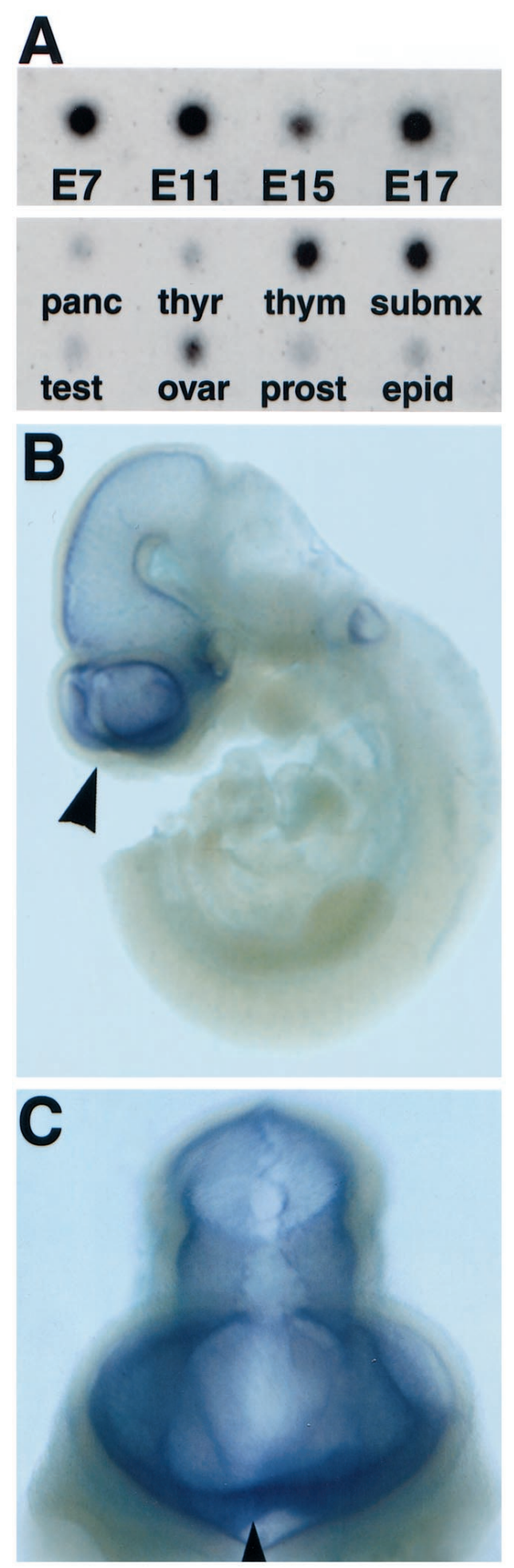

Figure 2. Expression of traf6 during embryonic development. Northern blot analysis of traf6 mRNA prepared from wild-type adult tissues and whole embryos at E7, E11, E15, and E17, showing relative levels of traf6 expression. panc, Pancreas; thyr, thyroid; thym, thymus; submx, submaxillary; test, testes; ovar, ovary; prost, prostate; epid, epididymus. B, In situ hybridization of a whole mount of an E9.5 wild-type embryo showing traf6 expression in the developing brain. The highest levels of expression occur in the forebrain (arrowhead), with lower expression in the midbrain and hindbrain regions. $C$, Rostral view (magnified) of the embryo in $B$ showing traf6 expression in the developing forebrain (arrowhead).

\section{Analysis of neural migration and CNS development in TRAF6-deficient embryos}

Neural tube closure requires the proper coordination of several basic processes, including cell migration invoked by contactdependent signaling, cell proliferation, and apoptosis. To examine the developmental consequences of TRAF6 deficiency with respect to cell migration and differentiation, the spatial distribution of several well characterized cellular markers, including the lowaffinity nerve growth factor receptor p75, calretinin, calbindin, tyrosine hydroxylase, and neuropeptide $\mathrm{Y}$, was examined using an immunohistochemical approach. The expression pattern of p75 in traf6 $(+/-)$ and $(-/-)$ embryos is shown in a series of paired photomicrographs in Figure 3, whereas patterns for the other markers appear in Figure 4. On the whole, the morphological changes observed in exencephalic traf6 $(-/-)$ embryos represent largely structural displacement rather than overt disruption of normal architecture. Although only medial sagittal sections are shown in Figures 3 and 4, the observed regional identities were based on serial sections obtained throughout the CNS proper (typically in two planes) for each of the indicated markers. The relative positions of structural features identified by each of these markers were subsequently compared between traf6 (-/-) exencephalic embryos and wild-type littermates. Summaries of regional comparisons between traf6 $(+/-)$ and $(-/-)$ embryos are shown as parts of Figures 5 and 6.

Because of the known interaction of TRAF6 with p75 (Khursigara et al., 1999; Ye et al., 1999), we first examined the expression of p75 in exencephalic traf6 $(-/-)$ mutants and wild-type or traf6 $(+/-)$ littermate controls at various stages of gestation. As shown in Figure 3 (color-coded arrows), comparable groups of neurons positive for p75 were present in traf6 $(+/-)$ (Fig. $3 A, C, E, G)$ and traf6 (-/-) (Fig. $3 B, D, F, H, I)$ embryos at both E14.5 (Fig. $3 A-$ $D, I)$ and E18.5 (Fig. $E-H$ ). Even within regions of prominent morphological perturbation, such as the cerebral cortex (which contained numerous aberrant invaginations), segments of organized cortical lamination could still be observed in traf6 $(-/-)$ embryos (Fig. 3, compare yellow arrowheads in $E, G$ and $F, H$ ). These data suggest that the loss of TRAF6 does not significantly alter the development of $\mathrm{p} 75^{+}$neurons.

Perturbations in the spatial distribution of several groups of $\mathrm{p} 75^{+}$neurons, however, were observed in exencephalic traf6 $(-/-)$ animals, most notably in neurons of the facial nucleus [Fig. 3, green arrowheads, compare $A(+/-)$ with $B, D, I(-/-)]$ and cerebellar Purkinje neurons [Fig. 3, black arrowheads, compare $A, G(+/-)$ with $B, F, H, I(-/-)]$. Neurons in these groups exhibited a substantially broader distribution in the hindbrain in exencephalic traf6 $(-/-)$ mice compared with control littermates, presumably because of alterations in neuronal survival and/or migration after eversion of the NT. Although the trigeminal ganglia [Fig. 3, red arrowheads, compare $C(+/-)$ with $B, D(-/-)]$ of traf6 $(-/-)$ embryos appeared somewhat enlarged at E14.5, analysis of the numbers of $\mathrm{p}^{+} 5^{+}$neurons within this site revealed no significant differences compared with controls (data not shown). Similarly, gross histological examination of traf6 $(-/-)$ dorsal root ganglia at E18.5 did not reveal significantly different numbers of $\mathrm{p} 75^{+}$neurons compared with controls (data not shown).

The patterns of expression of the additional neuronal markers calbindin, calretinin, tyrosine hydroxylase, and neuropeptide $\mathrm{Y}$ in traf6 $(+/-)$ and exencephalic traf6 $(-/-)$ embryos are shown in Figure 4. Calbindin, calretinin, and tyrosine hydroxylase were examined in a series of sagittal sections from E18.5 embryos. Similar expression patterns were observed in E14.5 (data not shown) and E18.5 embryos, but the cellular relationships were more easily defined at E18.5. The nonspecific staining in Figure 4, $B, D$, and $F$ (open arrowheads), represents intracerebral hemorrhaging frequently observed in exencephalic traf6 $(-/-)$ animals at this stage. Calbindin staining at E18.5 was comparable in traf6 $(+/-)$ and $(-/-)$ mice (Fig. 4, compare $A$ and $B$, yellow arrowhead). Equivalent staining for calretinin was also detected in traf6 $(+/-)$ and $(-/-)$ embryos (Fig. 4, compare $C$ and $D$, yellow 
A

Figure 3. Analysis of p75 expression in exencephalic TRAF6-deficient embryos. Paired photomicrographs $(A-B, C-D, E-F, G-H)$ of sagittal sections from representative traf6 $(+/-)(A, C, E$, $G)$ and exencephalic $(-/-)(B, D, F, H)$ littermates stained with anti-p 75 antibody. Section pairs are equivalent with respect to their mediallateral position to the sagittal midline. Sections are oriented such that rostral structures are located to the left and caudal structures to the right. Colored arrowheads denote the following structures: green, facial nucleus; red, trigeminal ganglion; black, $\mathrm{p} 75^{+}$Purkinje neurons of the cerebellum; yellow, $\mathrm{p} 75^{+}$cortical axons; orange, $\mathrm{p} 75^{+}$ inputs of developing fimbria-fornix; blue, $\mathrm{p} 75^{+}$ neurons of the developing thalamus; white, optic chiasma; gray, $\mathrm{p}^{+} 5^{+}$axons innervating dorsal spinal cord. $A, B$, Sagittal sections from E14.5 traf6 $(+/-)$ and $(-/-)$ embryos, $200 \mu \mathrm{m}$ from the sagittal midline. $C, D$, Matched E14.5 sections $500 \mu \mathrm{m}$ from the sagittal midline. $E, F$, Sagittal sections from E18.5 traf6 $(+/-)$ and $(-/-)$ embryos, $800 \mu \mathrm{m}$ from the sagittal midline. $G, H$, E18.5 sections showing the midbrain and hindbrain, $800 \mu \mathrm{m}$ from the sagittal midline. I, Sagittal section from an exencephalic E14.5 traf6 $(-/-)$ embryo, $300 \mu \mathrm{m}$ from the sagittal midline, showing the transition region of the facial nucleus. Scale bars: $\sim 1 \mathrm{~mm}$.
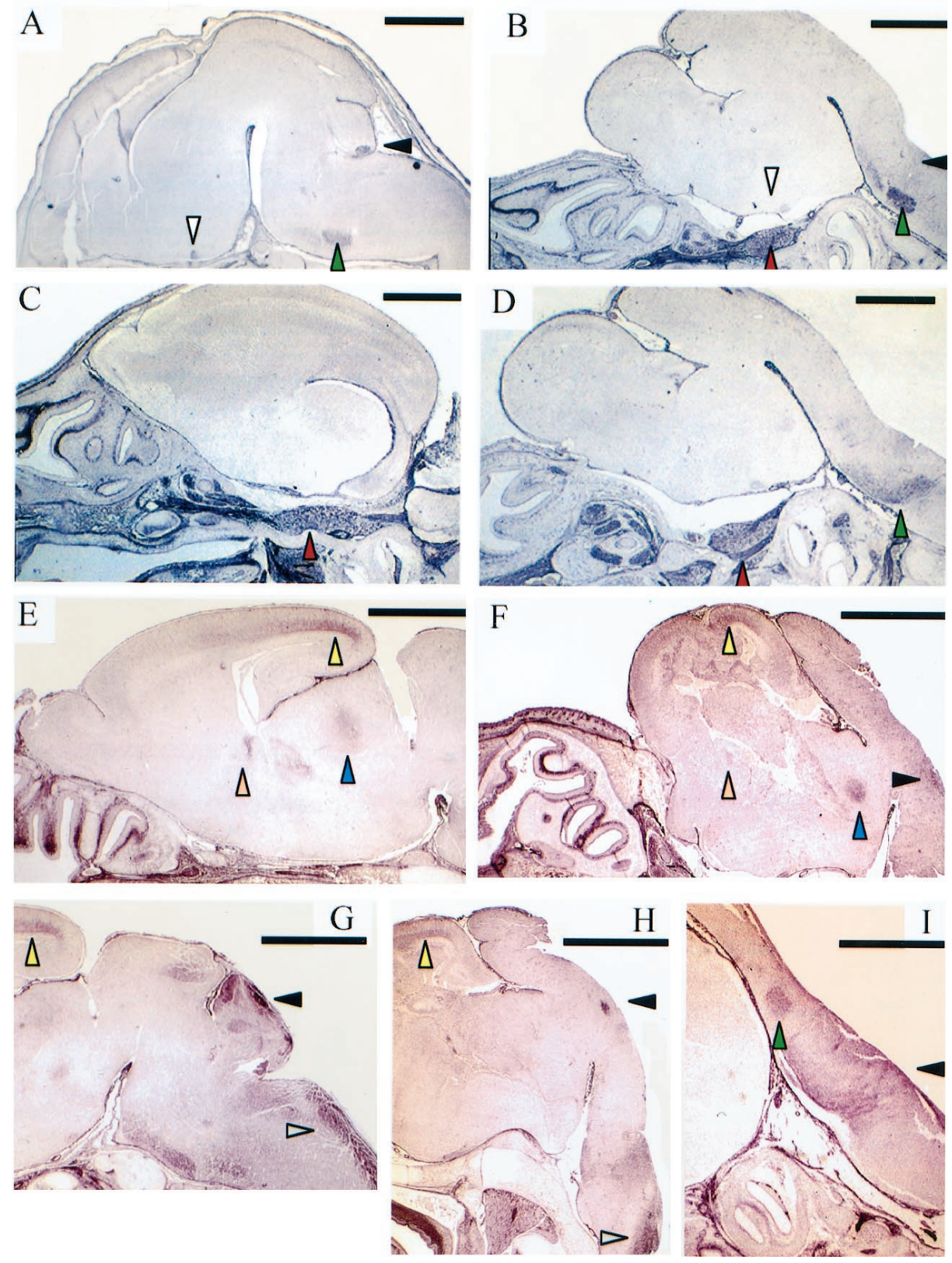

arrowhead). In traf6 (+/-) mice, these calcium-binding proteins identify clusters of interneurons bordering thalamic nuclei. The presence of calbindin- and calretinin-positive clusters in traf6 $(-/-)$ mice thus aids in delineating the position of comparable regions in traf6 $(-/-)$ mice. Similarly, tyrosine hydroxylase staining in E18.5 traf6 (+/-) and (-/-) embryos identified comparable regions of dopaminergic neurons located proximal to the midbrain-hindbrain junction (Fig. 4, compare $E$ and $F$, yellow arrowhead). Although substantially displaced in traf6 $(-/-)$ embryos, this boundary region can nonetheless be identified in the mutants.

In addition to alterations in the CNS, several changes in endocrine tissues were observed in exencephalic traf6 $(-/-)$ mice. Analysis of serial sections of traf6 (-/-) embryos stained for neuropeptide $\mathrm{Y}$ showed that the mutants sustained a substantial reduction in the size of their thyroid glands compared with heterozygous littermates (Fig. 4, compare $G$ and $H$, yellow arrowheads). In addition, the development of Rathke's pouch (primordium of the pituitary gland) was noticeably abnormal in traf6 $(-/-)$ mice compared with controls (Fig. 4, compare insets in $G$ and $H$ ).

Figure 5, $A$ and $B$, shows morphological summaries derived from the distribution of all neural markers examined from E12.5 to
E18.5 in traf6 (+/ $)$ and $(-/-)$ embryos. Comparison of these data indicates that the morphological disruption observed in exencephalic traf6 ( $-/-)$ mice is caused principally by cellular expansion of the hindbrain (yellow lines) and the ventral diencephalon (yellow arrowhead). In contrast, traf6 (-/-) mice exhibit a significant reduction in cerebral cortical volume (black arrow) and fewer nasal turbinates.

\section{Analysis of neuronal proliferation in TRAF6-deficient embryos}

To examine the mechanism underlying the regional hypertrophy observed in the hindbrain and ventral diencephalon of exencephalic traf6 $(-/-)$ mutants, the level of cell proliferation in traf6 $(+/+),(+/-)$, and $(-/-)$ animals was determined using BrdU immunohistochemistry. The pattern of BrdU labeling was assessed at E14.5, a period that follows the principal wave of neurogenesis that continues within secondary ventricular zones. Like heterozygous and wild-type littermates, the cortical tissue of E14.5 traf6 $(-/-)$ mice contained a secondary germinal zone (Fig. 5, compare $C-E$ with $F-H$ ), but the structure of the germinal zone was aberrant. In addition, multiple ectopic BrdU-labeled foci (Fig. 5G,H, 

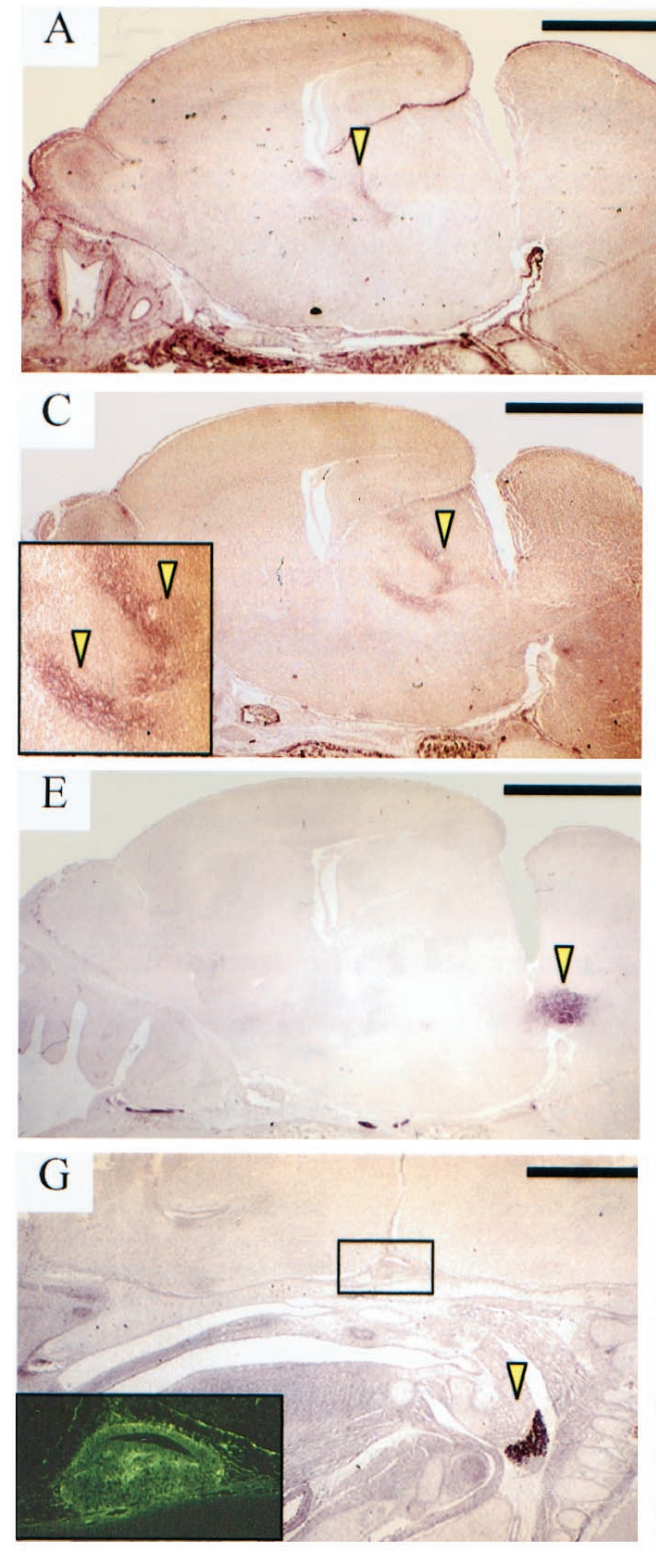
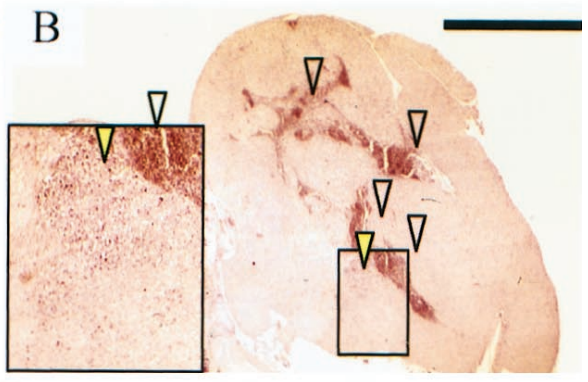

D
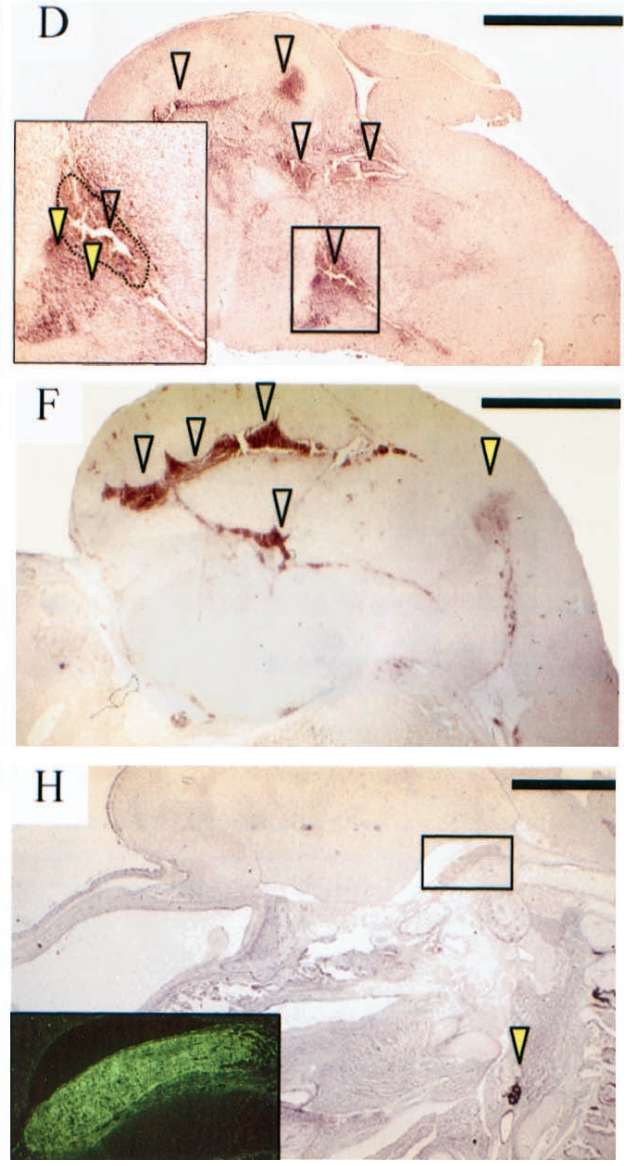

Figure 4. Immunohistochemical characterization of exencephalic TRAF6-deficient embryos. Each photomicrograph pair $(A-B$, $C-D, E-F, G-H)$ shows sagittal sections from the same traf6 $(+/-)(A, C, E, G)$ or exencephalic $(-/-)(B, D, F, H)$ littermates shown in Figure 3. Sections are oriented such that rostral structures are located to the left and caudal structures to the right. $A, B$, Calbindin staining of traf6 $(+/-)$ and $(-/-)$ littermates at E18.5. Sections are $\sim 750 \mu \mathrm{m}$ from the sagittal midline. $C, D$, Calretinin staining of E18.5 traf6 $(+/-)$ and $(-/-)$ embryos 850 $\mu \mathrm{m}$ from the sagittal midline. $E, F$, Tyrosine hydroxylase staining of E18.5 traf6 $(+/-)$ and $(-/-)$ embryos $950 \mu \mathrm{m}$ from the sagittal midline. Arrowheads denote particular groups of immunopositive neurons within the brains of traf6 $(+/-)$ embryos or their cellular equivalents in trafb $(-1-)$ mice as indicated in the Figure 3 legend. Scale bars, $1 \mathrm{~mm}$. Insets represent threefold magnifications of the adjacent boxed regions. $G, H$, Neuropeptide Y staining of E14.5 thyroid gland ( yellow arrowhead) of traf6 $(+/-)$ and $(-/-)$ embryos 100 $\mu \mathrm{m}$ from the sagittal midline. Insets show cross sections of Rathke's pouch. arrowheads) could be observed within the cortical tissue of traf6 $(-/-)$ embryos. However, although the overall level of BrdU incorporation appeared to be somewhat reduced in exencephalic traf6 ( $-/-)$ mice at E14.5, analysis of BrdU incorporation at earlier stages (E10-E12) did not demonstrate any significant differences between traf6 $(+/-)$ and $(-/-)$ mice (data not shown). We conclude that the deletion of TRAF6 does not induce the observed changes in CNS morphology by altering rates of cellular proliferation.

\section{Exencephalic TRAF6-deficient embryos exhibit regional- specific defects in programmed cell death}

In addition to neural proliferation, we examined the effect of TRAF6 deficiency on the pattern of PCD during embryonic development. TUNEL-labeled serial sections of E12.5-E14.5 traf6 $(+/-)$ and $(-/-)$ littermates were examined in relation to regional neural markers to delineate comparative regions within the developing CNS. Summaries of the CNS regions examined in traf6 $(+/-)$ and exencephalic $(-/-)$ mice are shown in Figure $6, A$ and $B$, respectively. TRAF6 $(-/-)$ embryos at E12.5-E14.5 showed substantially reduced levels of apoptosis within specific regions of the CNS compared with control littermates. A dramatic reduction $(>75 \%)$ in the level of TUNEL labeling was observed within the mutant ventral diencephalon at E14.5 (Fig. 6D, $F$, region 4) com- pared with heterozygous controls (Fig. 6C,E). A more modest reduction in $\mathrm{PCD}(60 \%)$ within this region was also observed at E15.5 for traf6 (-/-) mice (Fig. $6 H$ ) compared with controls (Fig. $6 G)$. In addition, a smaller but still significant decrease in PCD $(>20 \%)$ was observed within the mesencephalon of traf6 $(-/-)$ mice at E14.5 compared with controls (Fig. 6I,J, compare region 6). No significant differences in apoptosis were observed between traf6 $(-/-)$ mice and controls in the medulla oblongata, trigeminal ganglion, tongue epithelium, and nasal epithelium (Fig. 6, $K, L, M$, $N$, respectively; data shown for traf6 ( $-/-)$ samples only) or the retina, dorsal root ganglion, or superior cervical ganglion at E13.5E15.5 (data not shown). Interestingly, increased levels of apoptosis were observed in the cortex (region 1) of exencephalic traf6 $(-/-)$ embryos at E15.5 (data not shown). However, this increase in PCD appears to occur subsequent to the reductions in apoptosis observed within the ventral diencephalon and mesencephalon. Thus the results indicate that TRAF6 is involved in regulating PCD in several regions of the CNS during development.

\section{DISCUSSION}

In this study, we have examined the functional consequences of a null mutation of the traf6 gene on the development of the CNS in mice. Surprisingly, loss of TRAF6 had a striking effect on the 

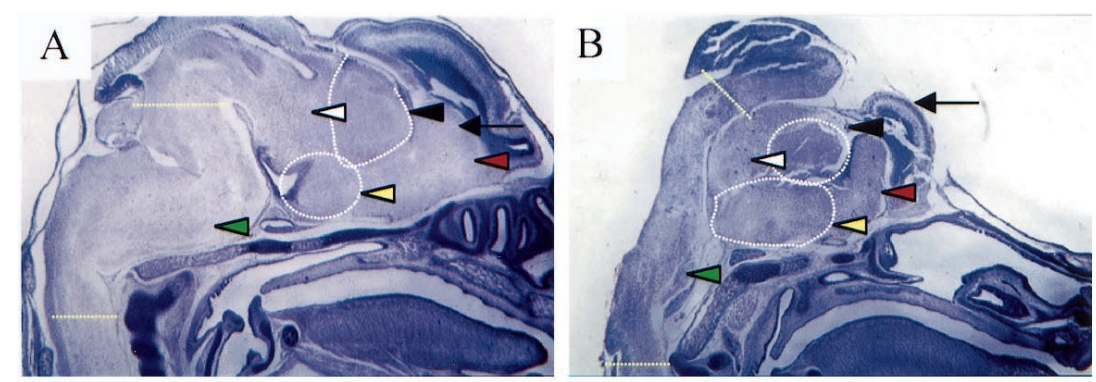

Figure 5. BrdU incorporation in exencephalic TRAF6-deficient embryos. $A, B$, Composite photomicrographs of thioninstained sagittal sections of E16.5 traf6 $(+/-)$ and $(-/-)$ embryos, respectively. Colored arrowheads indicate comparable cellular regions as determined by morphology, BrdU labeling, and immunohistochemical data. $C, F$, Sagittal overviews of BrdU labeling within the cerebral cortex of E14.5 trafb $(+/-)$ and exencephalic $(-/-)$ embryos, respectively. $D$, Magnified view of the boxed region shown in $C$. $E$, Additional view of BrdU labeling within the rostral cortex of a traf6 $(+/-)$ embryo at a similar level. $G$, Magnified view of the boxed region shown in $F$. $H$, Additional view of BrdU labeling within the cortex of a traf6 $(-/-)$ embryo at a level similar to that shown in $E$. In $G$ and $H$, the arrowheads denote regions of ectopic cell proliferation. Scale bars, $1 \mathrm{~mm}$.
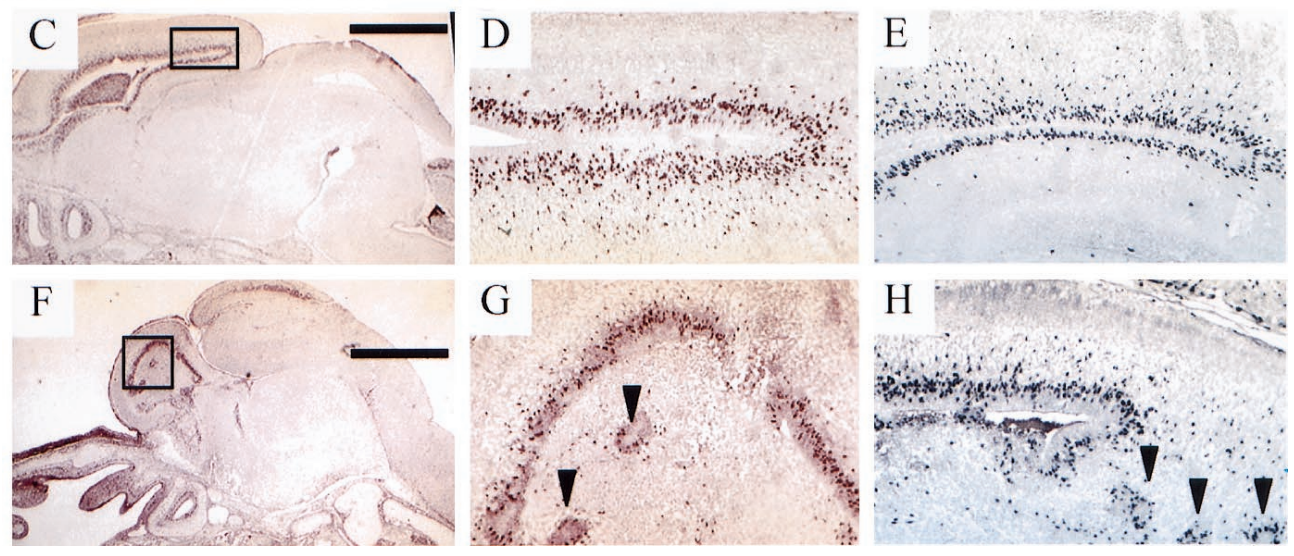

development of the CNS, resulting in exencephaly in a substantial subpopulation of traf6 $(-/-)$ mice. Because this condition is not compatible with survival, these mutant embryos die between E18 and $\mathrm{P} 0$. The number of live-born traf6 $(-/-)$ mice was found to vary substantially in different genetic backgrounds, suggesting that additional factors act in concert with TRAF6 to influence neural tube closure. This is perhaps not surprising given the multifactorial nature of this process as demonstrated previously for other neural tube mutants (Sah et al., 1995; Berk et al., 1997; Harris and Juriloff, 1999).

Exencephaly in TRAF6-deficient embryos was first observed at E10 and appears to result from a failure of NT closure in the region of the fourth ventricle. Specifically, neuroepithelia along the lateral edges of the NT fail to elevate properly, resulting in eversion of the NT. In addition, thickening of the neuroepithelia is observed along the lateral and rostral margins of the exposed NT. Thus, the NT defect in exencephalic traf6 (-/-) mice may be classified as a "zone B" failure in closure (Harris and Juriloff, 1999). Previous work on other zone B NT mutants has demonstrated that various mechanisms, including aberrant cell migration and proliferation, failure of overlying mesenchyme, deficiency of basal lamina, and dysregulation of neural apoptosis, can contribute to this process (Harris and Juriloff, 1999).

To determine the mechanism by which TRAF6 influences the development of the CNS, we examined structural morphology, BrdU incorporation, TUNEL staining, and the expression pattern of several immunohistochemical markers in traf6 $(+/+),(+/-)$, and $(-/-)$ littermates from E10 to E18.5. The results demonstrate that TRAF6 is more important in the CNS for the promotion of PCD rather than for influencing cellular migration or proliferation. Immunohistochemical analysis of BrdU incorporation did not reveal significant differences in the degree of cell proliferation in traf6 $(-/-)$ mutants compared with controls, except within the cortex where numerous invaginations and ectopic zones of neural proliferation were observed. Within this region, some increase in PCD was observed in traf6 $(-/-)$ mice compared with traf6 $(+/-)$ littermates. However, this increase in PCD is likely secondary to structural disruption of the cortex, given that it occurs subsequent to the reductions in PCD within the ventral diencephalon of traf6 $(-/-)$ mice. This may also be related to local disruptions in blood flow and perhaps other factors such as pressure-induced cortical hypoxia. In addition, it should be noted that although secondary germinal zones within the telencephalon were aberrant, segments of well organized laminar cortex could still be identified in traf6 $(-/-)$ embryos. This is in contrast to the previously reported phenotypes of exencephalic caspase 3, caspase 9, and Apaf-1 null mutants (Kuida et al., 1996; Hakem et al., 1998; Yoshida et al., 1998).

Analysis of TUNEL labeling in exencephalic traf6 (-/-) mutants suggests that the observed exencephaly results from cellular expansion of the ventral diencephalon, and to a lesser extent the hindbrain. The profound reduction in PCD within the ventral diencephalon of traf6 (-/-) embryos was characterized at E13.514.5, long after neural tube closure, and a significant reduction in PCD continued to be observed at E15.5. These data indicate that TRAF6 acts to regulate endogenous PCD within specific neural populations over a substantial developmental period known to be critical for proper functional organization of the CNS. For reasons of feasibility, the level of PCD was not examined at the time of NT closure (E8-E10); however it is possible that the defects observed in traf6 $(-/-)$ mice may relate to TRAF6-mediated changes in PCD. The presence of comparable groups of differentiated neurons in traf6 $(-/-)$ and wild-type mice suggests that loss of TRAF6 does not alter neural differentiation per se, but instead affects apoptosis in a region specific manner, which in turn results in the structural reorganization seen within the CNS of traf6 mutants.

As has been shown previously for a number of other proteins, we observe that the loss of TRAF6 has its greatest functional consequences in regions that do not necessarily correspond to its strongest sites of expression. These differences may be related to various factors, including the presence of structurally (or functionally) homologous proteins, variations in the level of upstream activators or downstream effectors within a cellular population, or variations in levels of modifiers that may alter the level of functional protein. In addition, within the nervous system it is important to consider that the site of mRNA production in neural cells may not necessarily reflect the spatial distribution of the functional protein.

With respect to the morphology of the exencephalic traf6 $(-/-)$ mice, it is interesting to note that these animals exhibit a striking similarity to embryos doubly deficient for jnk1 and jnk2 (Kuan et al., 1999; Sabapathy et al., 1999). Both traf6 (-/-) and jnk1/jnk2 $(-/-)$ mutants exhibit failure of NT closure at E9-E10 at the level of the fourth ventricle and show neuroepithelial thickening around 

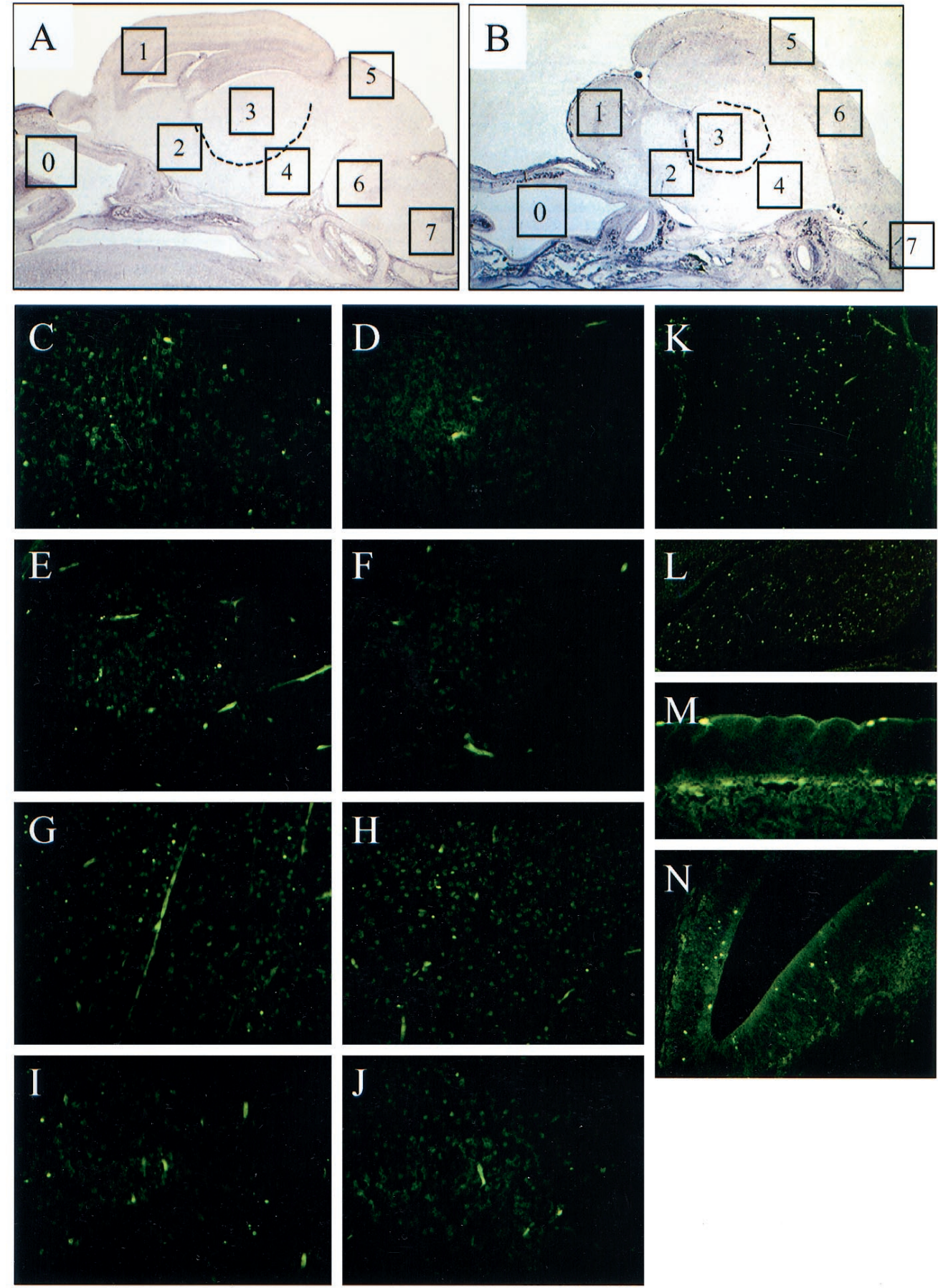
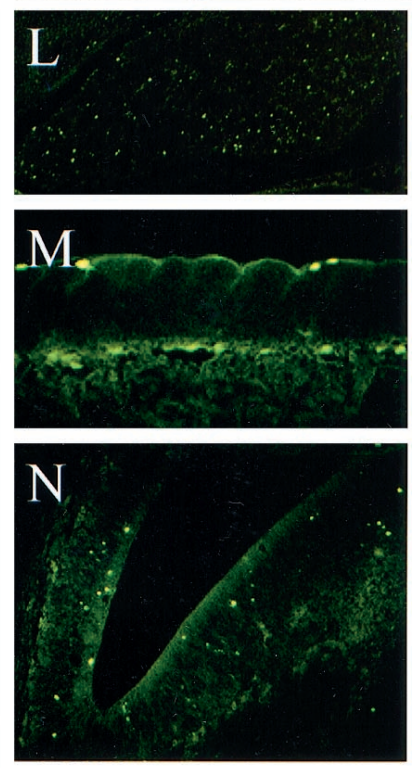

Figure 6. Reduction of programmed cell death in the CNS of exencephalic TRAF6-deficient embryos. $A, B$, Morphological summaries of the regions analyzed for TUNEL-positive neurons in E15.5 traf6 $(+/-)$ and exencephalic $(-/-)$ embryos, respectively. $C, E$, Two representative examples of TUNEL staining within the developing diencephalon (hypothalamus, region 4) of E14.5 traf6 $(+/-)$ embryos. $D, F$, Sections of traf6 $(-/-)$ littermates comparable with those in $C$ and $E$. $G, H$, TUNEL staining in region 4 of E15.5 traf6 $(+/-)$ and $(-/-)$ embryos, respectively. $I, J$, TUNEL staining within the diencephalon (thalamus, region 6$)$ of E14.5 traf6 $(+/-)$ and $(-/-)$ embryos, respectively. $K-N$, Representative examples of TUNEL staining within the $(K)$ medulla oblongata (region 7$),(L)$ trigeminal ganglion, $(M)$ tongue epithelium, and $(N)$ nasal epithelium (region 0 ) in E14.5 traf6 $(-/-)$ embryos. this region, resulting in eversion of the NT. Furthermore, both mutants exhibit a protrusion of brain tissue from the cranial vault, principally because of enlargement of the diencephalon. In both cases, this results in a lateral displacement of cortical tissue. Despite disruption in its overt structure, normal segments of cortical lamination are observed in both traf6 and jnk1/jnk2 mutants. Significant abnormalities in other structures such as the spinal cord, trigeminal ganglion, and dorsal root ganglia are not observed in either traf6 $(-/-)$ or $j n k 1 / j n k 2(-/-)$ embryos. Given the strong similarities between these two mutants, it will be of interest to determine whether TRAF6 is required for JNK activity during this period of CNS development.

The possibility that TRAF6 mediates JNK activity and NT closure in mammals is also supported by previous studies of the Drosophila gene Basket (Bsk), a homolog of JNK. Failure to activate $B s k$ leads to defective dorsal closure, a process in which lateral epithelial cells migrate over the embryo and join at the dorsal midline (Riesgo-Escovar et al., 1996; Sluss et al., 1996). Of the two Drosophila TRAFs identified to date, DTRAF2 shares most homology with mammalian TRAF6 (Liu et al., 1999). At present, the kinase(s) recruited by DTRAF2 is unknown; however, one logical candidate is Src42A, a Drosophila homolog of the mammalian proto-oncogene c-src (Tateno et al., 2000). Interestingly, flies mutated in Src42A exhibit a phenotype similar to those lacking Bsk, suggesting that the Bsk pathway is required downstream of Src42A in the dorsal closure pathway (Tateno et al., 2000). The hypothesized connection between DTRAF2 and Src42A stems from a recent study demonstrating the ability of the mammalian TRAF6 to interact with and enhance the kinase activity of c-src (Wong et al., 1999). It can thus be speculated that DTRAF2 may interact with and activate Src42A, which in turn stimulates Bsk during dorsal closure. A similar pathway may exist 
in mammals for the regulation of NT closure. A subset of c-srcdeficient mice has been reported to die in utero (Soriano et al., 1991), but it is unclear whether these embryos exhibited a "TRAF6-like" defect in NT closure leading to exencephaly.

In addition to c-src, there are a number of other intracellular molecules that interact with TRAF6, including transforming growth factor $\beta$ activating kinase (Ninomiya-Tsuji et al., 1999), apoptosis-signal regulating kinase (Hoeflich et al., 1999), and evolutionary conserved signaling intermediate in Toll pathways (Kopp et al., 1999). Any of these TRAF6-interacting proteins could be involved in regulating $\mathrm{JNK}$ phosphorylation and/or apoptosis. Recent studies have demonstrated that TRAF6 also interacts with the cell death-inducing kinase RIP2/RICK (McCarthy and Dixit, 1998), which in turn interacts with CARD4, a novel member of the CED-4/Apaf-1 family (Bertin et al., 1999). Thus, it is possible that TRAF6 recruits RIP2/RICK and/or CARD4, which in turn leads to induction of PCD. The generation of mutant mice deficient in these TRAF6-interacting proteins will help determine which one of them operates in a TRAF6-dependent signal transduction pathway involved in controlling NT fusion and apoptosis during CNS development.

TRAF6 has also been shown to interact with a number of cell surface receptors. The in vivo functions of many of these molecules, including IL-1R, CD40, RANK, and TLR4, have been characterized previously using gene-targeted mice (Kawabe et al., 1994; Glaccum et al., 1997; Dougall et al., 1999; Hoshino et al., 1999). However, the phenotype of exencephalic traf6 (-/-) mice does not closely parallel that of any of these null mutants, suggesting that the principal receptor(s) mediating NT fusion and PCD during development of the CNS has yet to be identified. Similarly, although TRAF6 has been reported to interact with the lowaffinity nerve growth factor receptor $\mathrm{p} 75$, the embryonic phenotype of both exencephalic and nonexencephalic traf6 $(-/-)$ mice differs markedly from that of p75-deficient mice. First, gross histological examination has shown that neither group of traf6 $(-/-)$ mice exhibits significant decreases in dorsal root ganglia or retinal apoptosis, in contrast to $p 75(-/-)$ mice. Second, viable traf6 $(-/-)$ mice do not exhibit signs of reduced cutaneous innervation, skin ulcerations, or defects in thermoception (data not shown). Last, viable, postnatal TRAF6-deficient mice exhibit progressive postnatal lethality at the time of weaning (Lomaga et al., 1999), in contrast to p75-deficient animals. At this point in our studies, however, we cannot exclude the possibility that TRAF6 mediates other aspects of postembryonic p75 signal transduction.

In conclusion, this study suggests a new role for TRAF6 in the development of the CNS. Through the generation and analysis of TRAF6-deficient embryos, we have demonstrated critical roles for TRAF6 in mediating NT closure and apoptosis, possibly through an as yet uncharacterized receptor. Our findings have the potential to contribute to the understanding of the genetic mechanisms underlying defects in NT closure.

\section{REFERENCES}

Arch RH, Gedrich RW, Thompson CB (1998) Tumor necrosis factor receptor-associated factors (TRAFs): a family of adapter proteins that regulates life and death. Genes Dev 12:2821-2830.

Berk M, Desai SY, Heyman HC, Colmenares C (1997) Mice lacking the ski proto-oncogene have defects in neurulation, craniofacial patterning, and skeletal muscle development. Genes Dev 11:2029-2039.

Bertin J, Nir WJ, Fischer CM, Tayber OV, Errada PR, Grant JR, Keilty JJ, Gosselin ML, Robison KE, Wong GH, Glucksmann MA, DiStefano PS (1999) Human CARD4 protein is a novel CED-4/Apaf-1 cell death family member that activates NF-kappa B. J Biol Chem 274:1295512958.

Cao Z, Xiong J, Takeuchi M, Kurama T, Goeddel DV (1996) TRAF6 is a signal transducer for interleukin-1. Nature 383:443-446.

Copp AJ, Brook FA, Estibeiro JP, Shum ASW, Cockroft DL (1990) The embryonic development of mammalian neural tube defects. Prog Neurobiol 35:363-403.

del Barco Barrantes I, Elia AJ, Wunsch K, Hrabe de Angelis M, Mak TW, Rossant J, Conlon RA, Gossler A, de la Pompa JL (1999) Interaction between Notch signalling and Lunatic fringe during somite boundary formation in the mouse. Curr Biol 9:470-480.

de la Pompa JL, Aguirre V, Mak TW, Gutierrez-Ramos JC (1997) Whole mount in situ hybridization of mouse embryos. Immunol Methods 6:1185-1193.

Dougall WC, Glaccum M, Charrier K, Rohrbach K, Brasel K, DeSmedt T, Daro E, Smith J, Tometsko ME, Maliszewski CR, Armstrong A, Shen V, Bain S, Cosman D, Anderson D, Morrissey PJ, Peschon JJ, Schuh J (1999) RANK is essential for osteoclast and lymph node development. Genes Dev 13:2412-2424.

Glaccum MB, Stocking KL, Charrier K, Smith JL, Willis CR, Maliszewski C, Livingston DJ, Peschon JJ, Morrissey PJ (1997) Phenotypic and functional characterization of mice that lack the type 1 receptor for IL-1. J Immunol 159:3364-3371.

Hakem R, Hakem A, Duncan GS, Henderson JT, Woo M, Soengas MS, Elia A, de la Pompa JL, Kagi D, Khoo W, Potter J, Yoshida R, Kaufman SA, Lowe SW, Penninger JM, Mak TW (1998) Differential requirement for caspase 9 in apoptotic pathways in vivo. Cell 94:339-352.

Harris MJ, Juriloff DM (1999) Mini-review: toward understanding mechanisms of genetic neural tube defects in mice. Teratology 60:292-305.

Hoeflich KP, Yeh W-C, Yao Z, Mak TW, Woodgett JR (1999) Mediation of TNF receptor-associated factor effector functions by apoptosis signalregulating kinase-1 (ASK1). Oncogene 18:5814-5820.

Hoshino K, Takeuchi O, Kawai T, Sanjo H, Ogawa T, Takeda Y, Takeda K, Akira S (1999) Toll-like receptor 4 (TLR4)-deficient mice are hyporesponsive to lipopolysaccharide: evidence for TLR4 as the lps gene product. J Immunol 162:3749-3752.

Kawabe T, Naka T, Yoshida K, Tanaka T, Fujiwara H, Suematsu S, Yoshida N, Kishimoto T, Kikutani H (1994) The immune responses in CD40-deficient mice: impaired immunoglobulin class switching and germinal centre formation. Immunity 1:167-178.

Khursigara G, Orlinick JR, Chao MV (1999) Association of the p75 neurotrophin receptor with TRAF6. J Biol Chem 274:2597-2600.

Kopp E, Medzhitov R, Carothers J, Xiao C, Douglas I, Janeway CA, Ghosh S (1999) ECSIT is an evolutionarily conserved intermediate in the Toll/IL-1 signal transduction pathway. Genes Dev 13:2059-2071.

Kuan C-Y, Yang DD, Samata-Roy DR, Davis RJ, Rakic P, Flavell RA (1999) The Jnk1 and Jnk2 protein kinases are required for regional specific apoptosis during early brain development. Neuron 22:667-676.

Kuida K, Zheng TS, Na S, Kuan C, Yang D, Karasuyama H, Rakic P, Flavell RA (1996) Decreased apoptosis in the brain and premature lethality in CPP32-deficient mice. Nature 384:368-372.

Liu H, Su Y-C, Becker E, Treisman J, Skolnik EY (1999) A Drosophila TNF-receptor-associated factor (TRAF) binds the Ste20 kinase Misshapen and activates Jun kinase. Curr Biol 9:101-104.

Lomaga MA, Yeh W-C, Sarosi I, Duncan GS, Furlonger C, Ho A, Morony S, Capparelli C, Van G, Kaufman S, van der Heiden A, Itie A, Wakeham A, Khoo W, Sasaki T, Cao Z, Penninger JM, Paige CJ, Lacey DL, Dunstan CR, Boyle WJ, Goeddel DV, Mak TW (1999) Traf6 deficiency results in osteopetrosis and defective interleukin-1, CD40, and LPS signaling. Genes Dev 13:1015-1024.

McCarthy JV, Dixit VM (1998) RIP2 is a novel NF-kappa B-activating and cell-death-inducing kinase. J Biol Chem 273:16968-16975.

Muhlenbeck WH, Scheurich P (1998) Identification of a TRAF (TNF receptor-associated factor) gene in Caenorhabditis elegans. J Mol Evol 47:656-662.

Naito A, Azuma S, Tanaka S, Miyazaki T, Takaki S, Takatsu K, Nakano K, Nakamura K, Katsuki M, Yamamoto T, Inoue J (1999) Severe osteopetrosis, defective interleukin-1 signalling and lymph node organogenesis in TRAF6-deficient mice. Genes Cells 4:353-362.

Nakano H, Sakon S, Koseki H, Takemori T, Tada K, Matsumoto M, Munechika E, Sakai T, Shirasawa T, Akiba H, Kobata T, Santee S, Ware CF, Rennert PD, Taniguchi M, Yagita H, Okumura K (1999) Targeted disruption of Traf5 gene causes defects in CD40- and CD27-mediated lymphocyte activation. Proc Natl Acad Sci USA 96:9803-9808.

Neumann PE, Frankel WN, Letts VA, Coffin JM, Copp AJ, Bernfield M (1994) Multifactorial inheritance of neural tube defects: localization of the major gene and recognition modifiers in ct mutant mice. Nat Genet 6:357-362.

Ninomiya-Tsuji J, Kishimoto K, Hiyama A, Inoue J, Cao Z, Matsumoto K (1999) The kinase TAK1 can activate the NIK-I kappa B as well as the MAP kinase cascade in the IL-1 signalling pathway. Nature 398:252-256.

Riesgo-Escovar JR, Jenni M, Fritz A, Hafen E (1996) The Drosophila jun-n-terminal kinase is required for cell morphogenesis but not for djun-dependent cell fate specification in the eye. Genes Dev 10:27592768.

Rothe M, Wong SC, Henzel WJ, Goeddel DV (1994) A novel family of putative signal transducers associated with the cytoplasmic domain of the $75 \mathrm{kDa}$ tumor necrosis factor receptor. Cell 78:681-692.

Rothe M, Sarma V, Dixit VM, Goeddel DV (1995) TRAF2-mediated activation of NF-kappa $\mathrm{B}$ by TNF receptor 2 and CD40. Science 269:1424-1427.

Sabapathy K, Jochum W, Hochedlinger K, Chang L, Karin M, Wagner EF (1999) Defective neural tube morphogenesis and altered apoptosis in the absence of both JNK1 and JNK2. Mech Dev 89:115-124.

Sah VP, Attardi LD, Mulligan GJ, Williams BO, Bronson RT, Jacks T 
(1995) A subset of p53-deficient embryos exhibit exencephaly. Nat Genet 10:175-180.

Sluss HK, Han Z, Barrett T, Davis RJ, Ip YT (1996) A jnk signal transduction pathway mediates morphogenesis and immune response in Drosophila. Genes Dev 10:2745-2758.

Smith JL, Schoenwolf GC (1997) Neurulation: coming to closure. Trends Neurosci 20:510-517.

Soriano P, Montgomery C, Geske R, Bradley A (1991) Targeted disruption of the c-src proto-oncogene leads to osteopetrosis in mice. Cell 64:693-702.

Takeuchi M, Rothe M, Goeddel DV (1996) Anatomy of TRAF2. Distinct domains for nuclear factor-kappa B activation and association with tumor necrosis signaling proteins. J Biol Chem 271:19935-19942.

Tateno M, Nishida Y, Adachi-Yamada T (2000) Regulation of JNK by Src during Drosophila development. Science 287:324-327.

Wong BR, Besser D, Kim N, Arron JR, Vologodskaia M, Hanafusa H, Choi Y (1999) TRANCE, a TNF family member, activates Akt/PKB through a signaling complex involving TRAF6 and c-src. Mol Cell 4:1041-1049.

Xu Y, Cheng G, Baltimore D (1996) Targeted disruption of TRAF3 leads to postnatal lethality and defective T-dependent immune responses. Immunity 5:407-415.

Ye X, Mehlen P, Rabizadeh S, VanArsdale T, Zhang H, Shin H, Wang JJ, Leo E, Zapata J, Hauser CA, Reed JC, Bredesen DE (1999) TRAF family proteins interact with the common neurotrophin receptor and modulate apoptosis induction. J Biol Chem 274:30202-30208.

Yeh WC, Shahinian A, Speiser D, Kraunus J, Billia F, Wakeham A, de la Pompa JL, Ferrick D, Hum B, Iscove N, Ohashi P, Rothe M, Goeddel DV, Mak TW (1997) Early lethality, functional NF-kB activation, and increased sensitivity to TNF-induced cell death in TRAF2-deficient mice. Immunity 71:715-725.

Yoshida H, Kong Y-Y, Yoshida R, Elia AJ, Hakem A, Hakem R, Penninger JM, Mak TW (1998) Apaf1 is required for mitochondrial pathways of apoptosis and brain development. Cell 94:739-750. 